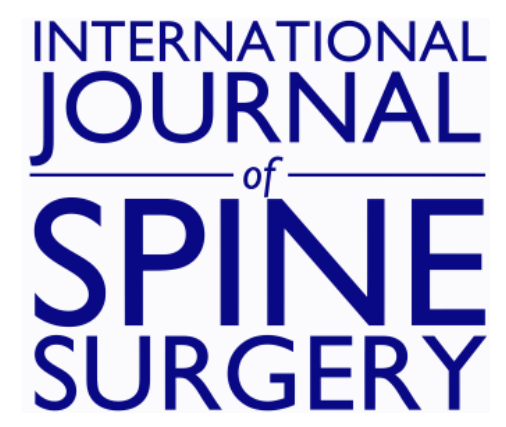

\title{
Demographic Trends in the Use of Intraoperative Neuromonitoring for Scoliosis Surgery in the United States
}

Remi M. Ajiboye, Howard Y. Park, Jeremiah R. Cohen, Evan E. Vellios, Elizabeth L. Lord, Adedayo O. Ashana, Zorica Buser and Jeffrey C. Wang

Int J Spine Surg 2017, 11 (5)

doi: https://doi.org/10.14444/4033

http://ijssurgery.com/content/11/5/33

This information is current as of April 25, 2023.

Email Alerts Receive free email-alerts when new articles cite this article. Sign up at:

http://ijssurgery.com/alerts

The International Journal of Soding Surgerght 2397 Waterbury Circle, Suite 1,

Aurora, IL 60504, Phone: +1-630-375-1432

(C) 2017 ISASS. All Rights Reserved. 


\section{Demographic Trends in the Use of Intraoperative Neuromonitoring for Scoliosis Surgery in the United States}

Remi M. Ajiboye MD, ${ }^{1}$ Howard Y. Park MD, ${ }^{1}$ Jeremiah R. Cohen BS, ${ }^{1}$ Evan E. Vellios MD, ${ }^{1}$ Elizabeth L. Lord MD, ${ }^{1}$ Adedayo O. Ashana MD, ${ }^{1}$ Zorica Buser $P h D,{ }^{2}$ Jeffrey C. Wang $M D^{2}$

${ }^{1}$ UCLA Medical Center, Department of Orthopaedic Surgery, Los Angeles, CA, ${ }^{2}$ Keck Medicine of USC, Department of Orthopaedic Surgery, Los Angeles, $C A$

\section{Abstract}

Background

Intraoperative neuromonitoring (ION) such as motor-evoked potential (MEP), somatosensory evoked potentials (SSEP) and electromyography (EMG) are used to detect impending neurological injuries during spinal surgery. To date, little is known on the trends in the use of ION for scoliosis surgery in the United States.

\section{Methods}

A retrospective review was performed using the PearlDiver Database to identify patients that had scoliosis surgery with and without ION from years 2005 to 2011. Demographic information (such as age, gender, region within the United States) and clinical information (such as type of ION and rates of neurological injury) were assessed.

\section{Results}

There were 3618 patients who had scoliosis surgery during the study period. ION was used in $1361(37.6 \%)$ of these cases. The number of cases in which ION was used increased from $27 \%$ in 2005 to $46.9 \%$ in 2011 ( $p<0.0001)$. Multimodal ION was used more commonly than unimodal ION (64.6\% vs. 35.4\%). The most commonly used modality was combined SSEP and EMG while the least used modality was MEP only. Neurological injuries occurred in $1.8 \%$ and $2.0 \%$ of patients that had surgery with and without ION, respectively $(\mathrm{p}=0.561)$. ION was used most commonly in patients $<65$ years of age and in the Northeastern part of the United States (age; $p=0.006$, region; $\mathrm{p}<0.0001)$.

\section{Conclusions}

The use of ION for scoliosis surgery gradually increased annually from 2005 to 2011 . Age and regional differences were noted with neuromonitoring being most commonly used for scoliosis surgery in non-elderly patients and in the Northeastern part of the United States. No differences were noted in the risk of neurological injury in patients that had surgery with and without ION. Although the findings from this study may seem to suggest that ION may not influence the risk of neurologic injury, this result must be interpreted with caution as inherently riskier surgeries may utilize ION more, leading to an actual reduction in injuries more dramatic than observed in this study.

OTHER AND SPECIAL CATEGORY

KEYWORDS: SCOLIOSIS, NEUROMONITORING, MOTOR-EVOKED POTENTIAL, SOMATOSENSORY EVOKED POTENTIAL, ELECTROMYOGRAPHY

VOLUME 11 ISSUE 5 DOI: 10.14444/4033

PAGES $271-277$

\section{Introduction}

Neurological injuries are known complications of spine surgery. In spinal deformity surgery, the risk of neurological injury is estimated to be $0.5 \%$ to $3 \%{ }^{1-7}$ These injuries are thought to occur from implantrelated damages, correction maneuvers or ischemia. ${ }^{8}$ To decrease the risk of these adverse events, intraoperative neuromonitoring (ION) such as motorevoked potential (MEP), somatosensory evoked po- tential (SSEP) and electromyography (EMG) are used to detect impending injury of neural elements. SSEPs have been used clinically since 1977 and work by monitoring the ascending sensory afferent pathways in the spinal cord. ${ }^{9}$ MEPs work by monitoring peripheral muscle activity from direct stimulation of the motor cortex, while (triggered or spontaneous) EMGs monitor muscle contractions from nerve root stimulation. Prior to the widespread use of ION, the Stagnara wake-up test served as the only way to as- 
sess the functional integrity of the spinal cord intraoperatively. ${ }^{10}$ The Stagnara wake-up test is performed by waking a patient up during surgery and checking for gross motor movements. Some surgeons advocate for the adjunctive use of the Stagnara wakeup test when there is no improvement in ION signals despite actions to reverse a suspected intraoperative neurological injury or when reliable ION signals cannot be obtained. ${ }^{11}$

In 2009, the scoliosis research society (SRS) released an updated position statement stating that ION is the preferred method for early detection of an evolving or impending neurological injury during deformity surgery. ${ }^{12}$ However, the decision to use ION during spinal deformity surgery is often guided by the type of surgery, surgeon choice and experience, and there is no consensus on the optimal neuromonitoring modality to use. In addition, most of the published studies on the use of ION for scoliosis surgery are from academic centers and little is known on how neuromonitoring is used in the "real world" i.e. in academic and non-academic settings. The goal of this study was to evaluate the trends in the use of neuromonitoring for scoliosis surgery in the United States.

\section{Materials and Methods}

A retrospective review was performed using the PearlDiver Patient Record Database (www.pearldiver.com; PearlDiver, Inc., Warsaw, IN, USA) to search through the patient records within both the Standard Analytical Files (SAF) of Medicare and the United Healthcare (UHC) databases. The PearlDiver database is commercially available and contains de-identified patient data that is Health Insurance Portability and Accountability Act (HIPAA) compliant and allows researchers to construct queries to identify patient groupings that meet specified criteria of interest. The raw datasets are filtered by characteristics such as age group, gender, region of the country, and year. The SAF dataset used in this study spans from 2005-2011 and contains more than 40 million patients per year whereas the UHC set contains 21 million patients with records from 2007-2011.

\section{Data collection}

The database was used to identify cases of scoliosis undergoing spinal surgery with neuromonitoring from years 2005 to 2011 using both current procedural terminology (CPT) and international classification of diseases, ninth revision (ICD-9) codes (see appendix). Each record provided demographic information (such as age, gender, and region within the United States) and clinical information (such as type of neuromonitoring modality used and rates of neurological injury (See appendix). Neurologic injury was defined as neurologic weakness within 30 days after the index surgery.

\section{Statistical analysis}

The STATA statistical software version 11.0 (STATACorp, College Station, TX) was used to perform the analyses. The chi-square test was used to detect any differences in the variables of interest (i.e. temporal trends, complications, age, gender, and region). Significance level was set at the $\mathrm{p}<0.05$.

\section{Results}

Neuromonitoring use in the United States during the study period (2005 - 2011)

During the study period, 3618 patients underwent scoliosis surgery. Overall, neuromonitoring was used in 1361 (37.6\%) of these cases. There was a statistically significant steady increase in the use of neuromonitoring for scoliosis surgery from $27 \%$ in 2005 to $46.9 \%$ in 2011 ( $\mathrm{p}<0.0001)$ (Figure 1, Table 1).

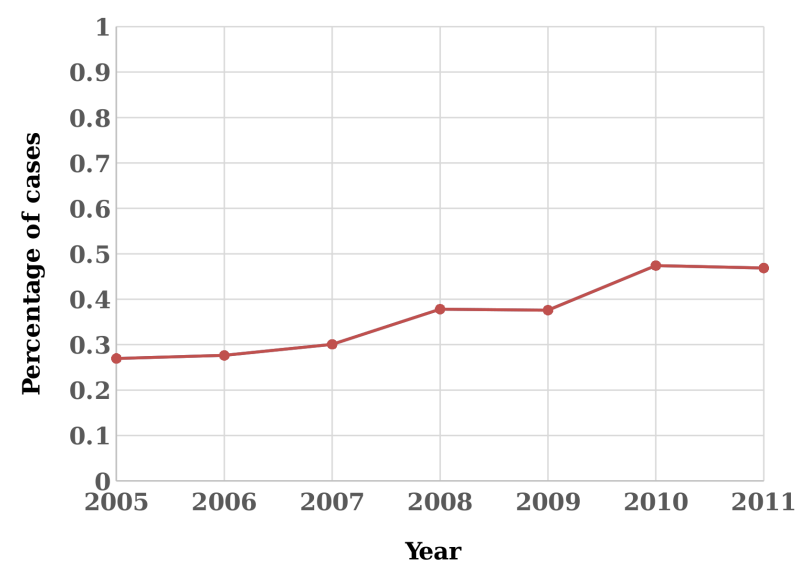

Fig. 1. Percentage of scoliosis surgery performed with neuromonitoring during the study period (2005-2011). 
Type of neuromonitoring modality

Out of a total of 1361 patients that had scoliosis

Table 1. Demographic information of patients from 2005 to 2011.

\begin{tabular}{|c|c|c|c|}
\hline & $\begin{array}{r}\text { Total number of scoliosis } \\
\text { surgery with neuromonitoring }\end{array}$ & $\begin{array}{l}\text { Total number of } \\
\text { scoliosis surgery }\end{array}$ & $\begin{array}{l}p- \\
\text { value }\end{array}$ \\
\hline Year & & & $\begin{array}{r}\mathrm{p}< \\
0.0001\end{array}$ \\
\hline 2005 & 93 & 345 & \\
\hline 2006 & 123 & 445 & \\
\hline 2007 & 154 & 512 & \\
\hline 2008 & 213 & 563 & \\
\hline 2009 & 258 & 686 & \\
\hline 2010 & 183 & 386 & \\
\hline 2011 & 195 & 416 & \\
\hline Age & & & $\begin{array}{r}p= \\
0.006\end{array}$ \\
\hline$<65$ & 255 & 580 & \\
\hline $65-69$ & 372 & 1002 & \\
\hline 70-74 & 337 & 931 & \\
\hline 75-79 & 267 & 741 & \\
\hline $80-84$ & 113 & 352 & \\
\hline$>84$ & 30 & 88 & \\
\hline Gender & & & $\begin{array}{r}p= \\
0.106\end{array}$ \\
\hline Female & 935 & 2542 & \\
\hline Male & 421 & 1062 & \\
\hline Region & & & $\begin{array}{r}\mathrm{p}< \\
0.0001\end{array}$ \\
\hline Midwest & 336 & 919 & \\
\hline Northeast & 231 & 436 & \\
\hline South & 640 & 1516 & \\
\hline West & 341 & 852 & \\
\hline Total * & 1361 & 3618 & \\
\hline
\end{tabular}

* Discrepancies between total value and summation of values in each group are attributed to the transfer of patients between subgroups. surgery with neuromonitoring, multimodal neuromonitoring was used in $64.6 \%$ of cases compared to $34.6 \%$ with unimodal neuromonitoring. In terms of specific combinations of neuromonitoring, the most commonly used modality was SSEP+EMG while the least used modality was MEP only (SSEP+EMG = $37.4 \%, \mathrm{EMG}$ only $=22.9 \%, \mathrm{SSEP}+\mathrm{MEP}+\mathrm{EMG}=$ $20.8 \%$, SSEP only $=12.4 \%$, SSEP + MEP $=5.7 \%$, $\mathrm{MEP}+\mathrm{EMG}=0.8 \%$, and MEP only $=0 \%)($ Table 2$)$.

\section{Neurological injury}

Neurological injuries within 30 days from the date of the index surgery occurred in $1.8 \%(24 / 1361)$ and $2.0 \%(46 / 2257)$ of patients that underwent surgery with and without ION, respectively $(\mathrm{p}=0.561)$ (Table 3).

\section{Age}

Neuromonitoring was used in $44.0 \%(255 / 580), 37.1 \%$ (372/1002), 36.2\% (337/931), 36\% (267/741), 32.1\% $(113 / 352)$, and $34 \%(30 / 88)$ of patients in age groups $<65$ years, 65-69 years, 70-74 years, $75-79$ years, and 80 years and over, respectively $(\mathrm{p}=0.006)($ Table 1$)$.

Table 2. Types of neuromonitoring modality used for scoliosis surgery.

\begin{tabular}{|c|c|c|c|}
\hline \multicolumn{4}{|c|}{ Unimodal neuromonitoring } \\
\hline \multicolumn{3}{|l|}{ SSEP only } & 169 \\
\hline \multicolumn{3}{|l|}{ MEP only } & 0 \\
\hline \multicolumn{3}{|l|}{ EMG only } & 313 \\
\hline \multicolumn{4}{|c|}{ Multimodal neuromonitoring } \\
\hline \multicolumn{3}{|l|}{ SSEP and MEP } & 77 \\
\hline \multicolumn{3}{|l|}{ SSEP and EMG } & 509 \\
\hline \multicolumn{3}{|l|}{ MEP and EMG } & 11 \\
\hline \multicolumn{3}{|l|}{ SSEP, MEP and EMG } & 283 \\
\hline \multicolumn{3}{|l|}{ Total* } & 1361 \\
\hline \multicolumn{4}{|c|}{$\begin{array}{l}\text { *Discrepancies between total value and summation of values in each } \\
\text { group are attributed to the transfer of patients between subgroups. }\end{array}$} \\
\hline \multicolumn{4}{|c|}{$\begin{array}{l}\text { Table 3. Risk of neurological injury after scoliosis surgery with and } \\
\text { without neuromonitoring. }\end{array}$} \\
\hline & $\begin{array}{r}\text { With neuromoni- } \\
\text { toring }\end{array}$ & $\begin{array}{r}\text { Without neuromoni- } \\
\text { toring }\end{array}$ & $\begin{array}{l}\text { p- } \\
\text { value }\end{array}$ \\
\hline $\begin{array}{l}\text { Risk of neurological } \\
\text { injury }\end{array}$ & $24 / 1361(1.8 \%)$ & $46 / 2257(2.0 \%)$ & 0.561 \\
\hline
\end{tabular}


Gender

Neuromonitoring was used in $36.8 \%$ (935/2542) of women compared to $39.6 \%(421 / 1062)$ of men $(\mathrm{p}=$ 0.106) (Table 1).

\section{Region}

Neuromonitoring was used in 53\% (231/436) of scoliosis surgery in the Northeastern part of the United States compared to $42.2 \%(640 / 1516)$ in the South, $40.0 \%(341 / 852)$ in the West and 36.6\% (336/919) in the Midwest $(\mathrm{p}<0.0001)$ (Table 1).

\section{Discussion}

The goal of this study was to evaluate the trends in the use of neuromonitoring for scoliosis surgery in the United States. To that end, we found increased utilization rates of neuromonitoring from 2005 to 2011, the vast majority of monitoring was multimodal, and the risk of neurological injury was not significantly altered by its use. Although there were no gender-related differences noted in the utility of neuromonitoring, age and regional differences were noted with neuromonitoring being most commonly used for scoliosis surgery in non-elderly patients and in the Northeastern part of the United States.

ION has emerged as a component of the standard of care for scoliosis surgery with data from this study showing that its use has increased from 2005 to 2011. The intuitive reasons for the utility of ION is to raise warning against devastating neurologic complications that can be prevented with intervention such as reducing the degree of distraction, adjusting retractors, removing hardware, and minimizing the length of surgery ${ }^{13}$ In a retrospective study of 443,194 patients by James et al., the utilization of ION within the United States increased from $1 \%$ of all spine procedures in 2007 to $12 \%$ in 2011, which are lower than the $37.6 \%$ overall utilization rate in scoliosis surgery found in this study. ${ }^{14}$ This difference can be accounted for by the inclusion of a wide-range of spinal procedures including microdiscectomy in the study by James et al. These procedures traditionally do not utilize ION to the same degree as scoliosis surgery. Furthermore, studies have shown no clear benefit or even recommended against ION in certain "lowrisk" spinal procedures. ${ }^{15,16}$ In their single institution- al study of 4467 neurosurgical procedures performed at Texas Children's Hospital, Vadivelu et al. found ION use increased from 2008 to 2011 with surgeonrelated factors such as less than 10 years of practice and subspecialty interest in spine positively associated with its use. ${ }^{17}$ Although the inclusion criteria of the aforementioned studies may differ, the overall trend of increased ION utilization in the last decade is seemingly well established.

When considering the absolute utilization rate of $37.6 \%$ in our study, it may be interpreted as a low especially in comparison to a recent study of 108,419 procedures by members of the SRS morbidity and mortality committee in which ION was used in 65\% of cases. ${ }^{18}$ There are several factors that account for the differences in utilization rates for ION in both studies. Members of the SRS morbidity and mortality committee are primarily from high-performing academic centers that perform cases of higher complexity. This current study utilizes a national database, which captures practice patterns from both academic and non-academic centers. In addition, there may be over-coding for the diagnosis of "scoliosis" in this study as varying degrees of coronal deformity occur concurrently with lumbar stenosis and other "low-risk" spinal procedures. Lastly, the lack of availability of ION (especially in non-academic centers) and the increased cost associated with its use may account for the low overall utilization rate observed in the current study.

With regard to the specific modalities of use, we found that combined SSEP with EMG was the most commonly utilized modality. Unimodal neuromonitoring comprised only $35.3 \%$ of monitoring use in our study, which is somewhat comparable to the rate of 22.6\% reported by Hamilton et al. ${ }^{18}$ Multimodal ION is commonplace as it can monitor both spinal cord and nerve root function. ${ }^{19}$ Multimodal ION has resulted in increases in the sensitivity and specificity for neurologic injury to nearly $100 \% .{ }^{19-22}$

Neurologic injury within 30 days from the date of index surgery occurred in $1.8 \%$ and $2.0 \%$ of patients that underwent scoliosis surgery with and without ION, respectively. These rates are within the range of $0.5 \%$ to $3 \%$ risk of neurological injury reported in 
the literature for deformity surgeries. ${ }^{1-7}$ Although the findings from this study may seem to suggest that ION may not influence the rate of neurologic injury, this result must be interpreted with caution as inherently riskier surgeries may utilize neuromonitoring more leading to an actual reduction in injuries more dramatic than observed in this study. Fu et al. reported higher rates of neurologic deficits with ION in pediatric spine cases, which were attributed to the disproportionate use of monitoring in higher risk cases. ${ }^{23}$ To this end, no randomized-controlled trials have been undertaken to elucidate the true effect of neuromonitoring on neurological injuries following scoliosis surgery.

Our results revealed no difference with regard to gender, but showed a proclivity of ION to be utilized for scoliosis surgery more in non-elderly patients ( $<65$ years of age) and in the Northeastern region of the United States. To our knowledge, this is the first study to review the age or gender-related differences with respect to ION utilization. James et al. examined the regional use of neuromonitoring from 2008-2011 and the lowest utilization was noted to be in the Northeastern part of the United States, which conflicts with the results from our study. ${ }^{14}$ This difference may stem from the fact that our study exclusively studied scoliosis surgery as opposed to a heterogeneous group of neurosurgical spinal procedures examined by James et al. Within our dataset, the increased utility of ION in the Northeastern region of the United States may be influenced by medicolegal concerns and malpractice premiums in these areas. ${ }^{24}$ According to a recent report, the top five states with the highest medical malpractice payout per capita are New York, New Jersey, Pennsylvania, Massachusetts and Rhode Island, all of which are located in the Northeastern region of the United States. ${ }^{25}$ This finding highlights the fact that litigation and malpractice claims in various parts of the United States may have an influence on physicians' pattern of practice.

\section{Limitations}

There are some limitations inherent to using an administrative database for research. Inaccuracies in the coding of diagnosis and procedures codes may have influenced the results of this study. In addition, important detailed clinical information such as oper- ative time, disease severity, complexity of surgery, intraoperative events, neuromonitoring sensitivity, specificity, false positive and negatives, and information on type and severity of neurological complications are not recorded in this database. Despite these limitations, this study is valuable because it of its large sample size which makes it suitable to study national trends and captures a heterogeneous sample of the practice patterns of surgeons with regards to ION use for scoliosis surgery in both academic and non-academic centers. In addition, we believe that the information from this study will help shed light on disparities associated with neuromonitoring usage and/or availability across different regions of the United States especially in the current political and economic climate whereby healthcare cost and patient safety are currently being scrutinized.

\section{Conclusions}

The use of neuromonitoring for scoliosis surgery gradually increased annually from 2005 to 2011 . No differences were noted in the rates of neurological injury in patients that underwent scoliosis surgery with and without neuromonitoring. Although there were no gender-related differences noted in the utility of neuromonitoring, age and regional differences were noted with neuromonitoring being most commonly used for scoliosis surgery in non-elderly patients and in the Northeastern part of the United States.

\section{References}

1. Eggspuehler A, Sutter MA, Grob D, Jeszenszky $\mathrm{D}$, Dvorak J. Multimodal intraoperative monitoring during surgery of spinal deformities in 217 patients. European spine journal : official publication of the European Spine Society, the European Spinal Deformity Society, and the European Section of the Cervical Spine Research Society. 2007;16 Suppl 2:S188-196.

2. Diab M, Smith AR, Kuklo TR. Neural complications in the surgical treatment of adolescent idiopathic scoliosis. Spine. 2007;32(24):2759-2763.

3. Kamerlink JR, Errico T, Xavier S, et al. Major intraoperative neurologic monitoring deficits in consecutive pediatric and adult spinal deformity patients at one institution. Spine. 2010;35(2):240-245. 
4. Nuwer MR, Dawson EG, Carlson LG, Kanim LE, Sherman JE. Somatosensory evoked potential spinal cord monitoring reduces neurologic deficits after scoliosis surgery: results of a large multicenter survey. Electroencephalography and clinical neurophysiology. 1995;96(1):6-11.

5. Dawson EG, Sherman JE, Kanim LE, Nuwer MR. Spinal cord monitoring. Results of the Scoliosis Research Society and the European Spinal Deformity Society survey. Spine. 1991;16(8 Suppl):S361-364. 6. Forbes HJ, Allen PW, Waller CS, et al. Spinal cord monitoring in scoliosis surgery. Experience with 1168 cases. The Journal of bone and joint surgery. British volume. 1991;73(3):487-491.

7. Zhuang Q, Wang S, Zhang J, et al. How to make the best use of intraoperative motor evoked potential monitoring? Experience in 1162 consecutive spinal deformity surgical procedures. Spine.

2014;39(24):E1425-1432.

8. Malhotra NR, Shaffrey CI. Intraoperative electrophysiological monitoring in spine surgery. Spine. 2010;35(25):2167-2179.

9. Nash CL, Jr., Lorig RA, Schatzinger LA, Brown $\mathrm{RH}$. Spinal cord monitoring during operative treatment of the spine. Clinical orthopaedics and related research. 1977(126):100-105.

10. Vauzelle C, Stagnara P, Jouvinroux P. Functional monitoring of spinal cord activity during spinal surgery. Clinical orthopaedics and related research. 1973(93):173-178.

11. Leong JJ, Curtis M, Carter E, Cowan J, Lehovsky J. Risk of Neurological Injuries in Spinal Deformity Surgery. Spine. 2016;41(12):1022-1027. 12. Society SR. Position Statements: Neuromonitoring Information Statement. January 2009; https://www.srs.org/about-srs/quality-and-safety/ position-statements/neuromonitoring-informationstatement.

13. Nuwer MR, Emerson RG, Galloway G, et al. Evidence-based guideline update: intraoperative spinal monitoring with somatosensory and transcranial electrical motor evoked potentials*. Journal of clinical neurophysiology : official publication of the American Electroencephalographic Society. 2012;29(1):101-108.

14. James WS, Rughani AI, Dumont TM. A socioeconomic analysis of intraoperative neurophysiologi- cal monitoring during spine surgery: national use, regional variation, and patient outcomes. Neurosurgical focus. 2014;37(5):E10.

15. Resnick DK, Choudhri TF, Dailey AT, et al. Guidelines for the performance of fusion procedures for degenerative disease of the lumbar spine. Part 15: electrophysiological monitoring and lumbar fusion. Journal of neurosurgery. Spine. 2005;2(6):725-732. 16. Gundanna M, Eskenazi M, Bendo J, Spivak J, Moskovich R. Somatosensory evoked potential monitoring of lumbar pedicle screw placement for in situ posterior spinal fusion. The spine journal : official journal of the North American Spine Society.

2003;3(5):370-376.

17. Vadivelu S, Sivaganesan A, Patel AJ, et al. Practice trends in the utilization of intraoperative neurophysiological monitoring in pediatric neurosurgery as a function of complication rate, and patient-, surgeon-, and procedure-related factors. World neurosurgery. 2014;81(3-4):617-623.

18. Hamilton DK, Smith JS, Sansur CA, et al. Rates of new neurological deficit associated with spine surgery based on 108,419 procedures: a report of the scoliosis research society morbidity and mortality committee. Spine. 2011;36(15):1218-1228.

19. Pelosi L, Lamb J, Grevitt M, Mehdian SM, Webb JK, Blumhardt LD. Combined monitoring of motor and somatosensory evoked potentials in orthopaedic spinal surgery. Clinical neurophysiology : official journal of the International Federation of Clinical Neurophysiology. 2002;113(7):1082-1091.

20. Sutter MA, Eggspuehler A, Grob D, Porchet F, Jeszenszky D, Dvorak J. Multimodal intraoperative monitoring (MIOM) during 409 lumbosacral surgical procedures in 409 patients. European spine journal: official publication of the European Spine Society, the European Spinal Deformity Society, and the European Section of the Cervical Spine Research Society. 2007;16 Suppl 2:S221-228.

21. Quraishi NA, Lewis SJ, Kelleher MO, Sarjeant R, Rampersaud YR, Fehlings MG. Intraoperative multimodality monitoring in adult spinal deformity: analysis of a prospective series of one hundred two cases with independent evaluation. Spine.

2009;34(14):1504-1512.

22. Thuet ED, Winscher JC, Padberg AM, et al. Validity and reliability of intraoperative monitoring 
in pediatric spinal deformity surgery: a 23-year experience of 3436 surgical cases. Spine.

2010;35(20):1880-1886.

23. Fu KM, Smith JS, Polly DW, et al. Morbidity and mortality associated with spinal surgery in children: a review of the Scoliosis Research Society morbidity and mortality database. Journal of neurosurgery. Pediatrics. 2011;7(1):37-41.

24. The Medical Liability Monitor, Annual Survey, Annual Rate Survey. 2013.

25. Gower J. Medical Malpractive Payout Analysis. 2015.

\section{Disclosures \& COI}

The authors declare no relevant financial disclosures or conflicts of interest.

\section{Corresponding Author}

Remi M. Ajiboye, M.D., UCLA Department of Orthopaedic Surgery, 10833 LeConte Avenue, 76-119 CHS, Los Angeles, CA 90095-6902. Remi.Ajiboye@gmail.com.

Published 5 December 2017.

This manuscript is generously published free of charge by ISASS, the International Society for the Advancement of Spine Surgery. Copyright @ 2017 ISASS. To see more or order reprints or permissions, see http://ijssurgery.com. 